TAPROBANICA, ISSN 1800-427X. December, 2013. Vol. 05, No. 02: pp. 131-137.

(C) Taprobanica Private Limited, 146, Kendalanda, Homagama, Sri Lanka.

http://www.sljol.info/index.php/tapro

\title{
MIXED BREEDING SYSTEM AND ENTOMOPHILY IN Malachra capitata L. (MALVACEAE)
}

\section{P. Suvarna Raju ${ }^{1,2}$ and A. J. Solomon Raju ${ }^{1}$}

\footnotetext{
${ }^{1}$ Department of Environmental Sciences, Andhra University, Visakhapatnam 530 003, India

E-mail: ajsraju@yahoo.com ${ }^{2}$
}

\begin{abstract}
Malachra capitata is a small seasonal herb. Flowering occurs during September-October. It is hermaphroditic and self-compatible with a mixed breeding system. The conspicuous floral displays, non-tubular nature of the flower, and the small volume of nectar with high sugar concentration attract bees and butterflies with bees serving as the principal pollinator. The fruit set is $21 \%$ in openpollination mode despite the hectic foraging activity of bees and butterflies. The observed fruit set rate is attributed to the high percentage of flower predation by beetles, and by the nature of soil nutrient/environment requirements. The fruit is a schizocarp with five 1-seeded indehiscent mericarps. New plants arise from seed during the rainy season mostly at parental sites and usually form pure stands; the plants complete their life cycle within six or seven months.
\end{abstract}

Key words: mangrove associate, herb, insects, pollinator, soil binder, landward plant, India

\section{Introduction}

In India, there are a few studies made on the pollination biology of mangroves. Solomon Raju (1990) and Subba Reddi \& Solomon Raju (1997) provided some information on the floral biology of some mangroves in the state of Andhra Pradesh. These authors reported that pollen vectors are essential for fruit set in Caesalpinia nuga (L.) Ait. and Acanthus ilicifolius L. In A. corniculatum (L.) Blanco and Lumnitzera racemosa Willd., fruit set occurs principally through autogamy. In Avicennia officinalis L., the flowers are self-compatible but the sexual system promotes outcrossing.
Carpenter bees are the main pollinators for Caesalpina nuga, sunbirds for Acanthus ilicifolius, and flies for Avicennia officinalis. Solomon Raju et al. (1994) suggested that there is an urgent need for extensive studies on the reproductive biology of mangrove plants for their conservation and management. Based on the results of pollinator exclusion experiments, Pandit \& Choudhury (2001) reported that pollinators are important for the success of sexual reproduction in Aegiceras corniculatum and Sonneratia caseolaris (L.) Engl. An explosive pollination mechanism has been 
reported for Ceriops tagal (Perr.) C. B. Rob. and an non-explosive pollination mechanism in its sister species, $C$. decandra (Griff.) W. Theob.; both are adapted for insect pollination (Jonathan \& Solomon Raju, 2009; Solomon Raju \& Jonathan, 2008; Solomon Raju et al., 2006). Except for these studies, there is no information available on the pollination biology of other mangrove species, especially so for the so-called mangrove associates. Malachra capitata L. (Malvaceae) is a widely distributed herb found towards and along the landward side of the mangrove forests in general and especially in the Coringa mangrove forest of Andhra Pradesh, India. It has not been studied for any aspect of reproduction or regeneration and even its taxonomic description is incomplete. The intent of the present study is to provide details of floral biology, pollination and seed dispersal in M. capitata with reference to its importance as a source of forage for local insects.

\section{Materials and Methods}

Study site: The Coringa mangrove wetland lies between $16^{\circ} 30^{\prime}-17^{\circ} 00^{\prime} \mathrm{N}$ and $82^{\circ} 10^{\prime}-80^{\circ} 23^{\prime} \mathrm{E}$. Freshwater flows into the mangrove wetlands for a period of six months with peak flow normally during July-September, coinciding with the southwest monsoon season. During this period the entire delta, including the mangrove wetland, is submerged under freshwater since penetration of sea water is completely blocked by the large amount of incoming freshwater. Brackish water condition prevails from October to February and sea water dominates the entire mangrove wetland from March to May due to absence of freshwater discharge.

Floral presentation and reproductive traits: Field investigations and experiments were conducted on Malachra capitata from February 2010 to October 2012. The details of flower morphology such as flower sex, shape, size, colour, odour, sepals, petals, stamens and ovary were described. Anthesis and anther dehiscence schedule was recorded as per the protocol given in Dafni et al. (2005). The flower life was recorded by marking twenty just open flowers and following them until abscisions. Twenty mature but un-dehisced anthers were collected from five randomly selected plants to determine pollen output per anther/flower and then pollen-ovule ratio as per the protocol given by Cruden (1977). $\mathrm{An}_{2} \mathrm{O}_{2}$ test reported by Dafni et al. (2005) was followed to record the period of stigma receptivity. Nectar volume and sugar concentration was recorded as per the protocol given in Dafni et al. (2005).

Breeding system: Fifty flowers each from ten randomly selected plants were used for each mode of breeding system. The methods described by Dafni et al. (2005) were followed to test for apomixis, autogamy (manipulated and spontaneous), geitonogamy, and xenogamy. All these modes of pollination were followed for one month to calculate the percentage of fruit set in each mode. Two hundred flowers in different flowering patches were tagged in the field prior to anthesis and followed for fruit and seed set rate in openpollinations. Fruit maturation period, fruit dehiscence, seed dispersal, and establishment were also observed.

Observations and collection of floral foragers: The foragers included bees, butterflies and beetles. The species were identified based on comparisons with already identified specimens available in the department. They were observed for ten hours a day for fifteen days during the flowering season. The hourly foraging visits of each species of bee and butterfly species were recorded on ten different days in $1 \mathrm{x} 1 \mathrm{~m}$ flowering patch. The data obtained were used to calculate the percentage of foraging visits made by each species per day and the percentage of foraging visits of bees and butterflies per day. Simultaneously, the bees and butterflies were observed for their foraging behaviour such as mode of approach, landing, probing behaviour, the type of forage they collected, and contact with essential organs critical for pollination. These insects were captured during 1000-1200h on five different days for pollen analysis in the laboratory. For each bee and butterfly species, ten specimens were used and each specimen was washed first in ethyl alcohol and the contents stained with aniline-blue on a glass slide and observed under microscope to count the number of pollen grains present. For pollen collecting bees, pollen loads on their corbiculae were separated prior to washing. From pollen counts, the average number of pollen grains carried by these species was calculated to know their pollen carryover efficiency. In the case of 
beetles, they were observed for their flower feeding activity resulting in flower damage and subsequent fall off. A sample of five hundred flowers collected from different flowering patches was used for calculating the flower predation rate by beetles.

Photography: Plant, flower and fruit details, together the foraging activity of foragers, were documented with Nikon D40X Digital SLR (10.1 pixel) and TZ240 Stereo Zoom Microscope with SP-350 Olympus Digital Camera (8.1 pixel). Magnus Compound Microscope, 5x, 10x, 40x and 100x magnification was used for studying the pollen characteristics.

\section{Results}

Phenology: Malachra capitata is a small, coarse, erect, simple or branched annual herb which is covered with hairs. It is common along the margins of the landward low salinity areas of Coringa mangroves. It forms pure stands in areas lining the outermost land areas of mangroves and, as a mangrove associate, is an important soil-binding species. Leaf flushing and new growth occurs during the rainy season from June to August while flowering is from September to October. Flowers are borne axillary and in terminal heads; they are either solitary or in 2-4 flowered clusters. Pure flowering stands are attractive and give an aesthetic appeal.

The Flower: The flowers are pedicellate, medium-sized, showy, bisexual and actinomorphic. The epicalyx segments are three. The calyx lobes are five, short, 5-8 mm long, and slenderly pointed apically. The corolla has five, free, yellow petals in imbricate aestivation, $10-15 \mathrm{~mm}$ long, and united basally with the staminal tube. The stamens are numerous, yellow, monoadelphous; the filaments are united to form a short staminal tube but the filaments arise from all levels of the tube. The anthers are yellow, reniform and monothecous. The entire staminal column bends to one side of the flower. The ovary is superior with five united carpels (syncarpous); each carpel consists of a single ovule on axile placentation. The style passes through the staminal tube to a position above the stamens and branches at the top into exactly the same number as the locules, and each branch is terminated with a wet, capitate stigma.
Floral Biology: The mature flower buds open daily quickly during 0600-0800 h. Anther dehiscence takes place during mature bud stage by transverse slits at the top of the anthers; this divides the anther into two halves liberating the pollen grains. The pollen output per monothecous anther is $89 \pm 7.6$ (Range 80-98). The pollen grains are bright yellow, ellipsoidal, spinous, sticky, large and $134.8 \mu \mathrm{m}$ in size. A flower produces $1.8 \pm 0.13 \mu$ l of nectar with a sugar concentration of $37 \pm 1.9 \%$. The stigma attains receptivity one hour after anthesis and stays so until $1700 \mathrm{~h}$. The corolla, staminal column and stigma fall off by the evening of the second day. The calyx is persistent and harbours the growing fruit.

Breeding Systems: The results of breeding system studies indicate that the flowers are selfcompatible and capable of both self- and crosspollination. Fruit set is $4 \%$ in autogamy (unmanipulated), $24 \%$ in autogamy (manipulated), $38 \%$ in geitonogamy but $82 \%$ in xenogamy, and $21.2 \%$ in open-pollinations (Table 1). Seeds are produced by all modes of pollination. Bud and flower abortion was absent.

Table 1: Results of breeding experiments on Malachra capitata

\begin{tabular}{lccc}
\hline \multicolumn{1}{c}{$\begin{array}{c}\text { Breeding } \\
\text { system }\end{array}$} & $\begin{array}{c}\text { No. of } \\
\text { flowers } \\
\text { pollinated }\end{array}$ & $\begin{array}{c}\text { No. of } \\
\text { flowers } \\
\text { set fruit }\end{array}$ & $\begin{array}{c}\text { Fruit } \\
\text { set } \\
(\%)\end{array}$ \\
\hline $\begin{array}{l}\text { Apomixis } \\
\begin{array}{l}\text { Autogamy } \\
\text { (bagged) }\end{array}\end{array}$ & 50 & 0 & 0 \\
$\begin{array}{l}\text { Autogamy } \\
\text { (hand- }\end{array}$ & 50 & 2 & 4 \\
$\begin{array}{l}\text { pollinated and } \\
\text { bagged) }\end{array}$ & 50 & 12 & 24 \\
$\begin{array}{l}\text { Geitonogamy } \\
\text { Xenogamy }\end{array}$ & 50 & 19 & 38 \\
$\begin{array}{l}\text { Open } \\
\text { pollinations }\end{array}$ & 50 & 41 & 82 \\
\hline
\end{tabular}

Pollination and Pollinators: The funnelshaped flowers with a short, basal, corolla tube expose to foragers the entire length of the staminal column and stylar branches. They were foraged consistently from $0700-1800 \mathrm{~h}$. The foragers included bees of family Apidae: Apis dorsata, A. cerana, A. florea, Trigona iridipennis, Xylocopa latipes, and X. pubescens; ants of family Formicidae: Camponotus sp.; and butterflies Pachliopta aristolochiae (Papilionidae), Euploea core (Nymphalidae), 
and Borbo cinnara (Hesperiidae) (see Table 2). Of these, the honey bees (Apis and Trigona) collected both pollen and nectar while other bees, the ant and butterflies collected only nectar. All bee species displayed their foraging activity from 0700 to $1600 / 1700 \mathrm{~h}$ while the butterflies showed their activity from 0800 to $1500 / 1600 \mathrm{~h}$. The foraging activity pattern showed that both categories made more numerous visits during the forenoon period. The percentage of foraging visits varied with individual species. Apis dorsata, T. iridipennis and X. latipes each made 13\%; A. cerana, A. florea and $X$. pubescens each made $12 \%$; the butterflies visiting slightly less, $B$. cinnara $10 \%, P$. aristolochiae $9 \%$ and E. core $6 \%$. Within bees, the percentage of foraging visits of honey bees accounted for 50\% while carpenter bees for $25 \%$.

Table 2: List of insect foragers on Malachra capitata ( $\mathrm{P}$, pollen; $\mathrm{N}$, nectar)

\begin{tabular}{lc}
\hline \multicolumn{1}{c}{ Insect species } & Forage sought \\
\hline Apis dorsata & $\mathrm{P} / \mathrm{N}$ \\
Apis cerana & $\mathrm{P} / \mathrm{N}$ \\
Apis florea & $\mathrm{P} / \mathrm{N}$ \\
Trigona iridipennis & $\mathrm{P} / \mathrm{N}$ \\
Xylocopa pubescens & $\mathrm{N}$ \\
Xylocopa latipes & $\mathrm{N}$ \\
\hline Camponotus sp. & $\mathrm{N}$ \\
\hline Pachliopta aristolochiae & $\mathrm{N}$ \\
\hline Euploea core & $\mathrm{N}$ \\
\hline Borbo cinnara & $\mathrm{N}$ \\
\hline
\end{tabular}

Both the bees and butterflies approached the flowers in an upright position, landed on the petals and probed the flowers for forage with ease. The bees invariably contacted the stigma and got powdered with pollen all over their dorsal and ventral sides; the contact occurred while entering the flower probing for nectar or during departure from the flower. Butterflies also had contact with the stamens and stigma while extending the proboscis or during departure from the flower; in this case the stamens and stigma contacted their proboscis and wings. Body washings of bees and butterflies revealed the presence of scores of pollen grains; the mean number varied from 162.4 to 308.2 in bees and from 58.8 to 73.6 in butterflies (Table 3). These insects showed inter-plant foraging activity in search of more pollen and/or nectar; such forage collection behaviour was considered to be important in effecting both self- and cross-pollination.

Table 3: Pollen pick-up efficiency of foraging insects on Malachra capitata

\begin{tabular}{lcc}
\hline Insect species & $\begin{array}{c}\text { Range } \\
(\boldsymbol{n}=\mathbf{1 0})\end{array}$ & Mean \pm S.D \\
\hline A. dorsata & $173-367$ & $244 \pm 79.5$ \\
\hline A. cerana & $173-314$ & $235.8 \pm 59.2$ \\
A. florea & $67-291$ & $162.4 \pm 87.3$ \\
T. iridipennis & $77-321$ & $225.8 \pm 95.9$ \\
X. latipes & $218-356$ & $308.2 \pm 53.1$ \\
X. pubescens & $134-376$ & $238.2 \pm 95.7$ \\
\hline P. aristolochiae & $45-110$ & $73.6 \pm 23.8$ \\
\hline E. core & $39-81$ & $58.8 \pm 16.3$ \\
B. cinnara & $49-89$ & $66.4 \pm 15.1$ \\
\hline
\end{tabular}

The ant, Camponotus sp., was a resident forager and crawls on the entire plant and collected nectar from the flowers intermittently. It had contact with the stigma and stamens occasionally since it probed by crawling along the length of the petals which are spacious and would not permit the ant to have contact with the flower's sex organs. It could bring about pollination only to a limited extent.

Further, the flowers attracted three species of beetles, Brachinus sp. (Carabidae), Lygaeus hospes (Coccinellidae) and Mylabris phalerata (Meloidae). The first and last beetle fed slowly on the flowers, including stamens and stigma, while the second did not feed on the flowers but collected nectar occasionally. The flower predation rate by both Brachinus and $M$. phalerata was found to be $28 \%$.

All the studied aspects of pollination ecology are summarized in Table 4.

Fruiting Behavior: Pollinated and fertilized flowers mature within a month. The fruit is a globose schizocarp separating into individual mericarps. The number of mericarps is equivalent to number of seeds and their production is dependent on the number of fertilized ovules. Each mericarp is $3-3.5 \mathrm{~mm}$ long, muticous, papery, reddish veined, pubescent, and indehiscent. Seeds are trigonous, black, glabrous, and $2.5 \mathrm{~mm}$ long. The aerial stalks disappear following the dispersal of seeds. Seeds remain dormant through the winter and summer seasons and germinate in the rainy season which commences in June. Most of the seedlings were 
found to produce pure stands of plants in the parental sites and those dispersed away from parental sites also establish new plants but in smaller groups.

Table 4: Chronological events of sexual reproduction in Malachra capitata

\begin{tabular}{|cc|}
\hline Floral event & Malachra capitata \\
\hline Anthesis & $0600-0800 \mathrm{~h}$ \\
\hline Anther dehiscence & Mature bud \\
\hline Sepals & $\begin{array}{c}\text { Persistent; turns into } \\
\text { fruiting calyx }\end{array}$ \\
Petals & 2 days \\
Stamens & 2 days \\
\hline Stigma receptivity & $1^{\text {st }}$ day only \\
\hline Pollen output/anther & $89 \pm 7.6$ \\
\hline Pollen-ovule ratio & $\begin{array}{c}\text { Not calculated due to } \\
\text { numerous stamens }\end{array}$ \\
\hline Nectar volume/flower & $1.8 \pm 0.13$ \\
Nectar sugar & $37 \pm 1.9$ \\
concentration $(\%)$ & Entomophily \\
Pollination system & Bees and butterflies \\
\hline Pollinators & Self and cross \\
\hline Breeding system & 21.2 \\
\hline $\begin{array}{l}\text { Fruit set in open } \\
\text { pollinations }(\%)\end{array}$ & 28 \\
\hline Flower predation $(\%)$ & ca. 30 days \\
\hline $\begin{array}{c}\text { Fruit maturation time } \\
\text { (days) }\end{array}$ & $2-5$ \\
\hline Seed set per fruit & \\
\hline
\end{tabular}

\section{Discussion}

Malachra capitata is an annual herb which appears during rainy season. With complete leaf flushing and full growth of new leaves, it flowers for a period of two months. This short period of flowering seems to be sufficient to produce an optimal seed set rate with its selfcompatible and self- and cross-pollination systems. Further prolific growth and formation of pure stands attract pollinators and the latter exhibit fidelity to the plant due to availability of adequate forage in the form of pollen and nectar.

The anthesis schedules are available for some members of Malvaceae to which Malachra capitata belongs. The flower-opening occurs during 0700-0800 h in Sida cordifolia L., S. acuta Burm.f., Hibiscus vitifolius L., $H$. cannabinus L. and $H$. panduriformis Burm.f.; during 1000-1100 $\mathrm{h}$ in Abutilon hirtum (Lam.) Sweet, at $1400 \mathrm{~h}$ in A. graveolens (Roxb. ex Hornem) Wight \& Arn. and during 1400-1500 $\mathrm{h}$ in A. indicum (L.) Sweet. In the present study, $M$. capitata shows anthesis during morning period and presents both pollen and nectar at anthesis due to anther dehiscence and nectar secretion during bud stage. The dehiscence of anthers by transverse slits causes the monothecous anthers to split into two halves. This mode of anther dehiscence enables liberation of large and spinous pollen grains especially when pollen collecting insects probe them. This mode of dehiscence is the characteristic of Malvaceae members (Solomon Raju, 2007).

Gottsberger (1972) stated that Malvaceae are clearly a derived group from the woody members of Malvales. Gottsberger (1967; 1972) and Sazima (1981) reported that the life forms tend strongly towards an herbaceous growth pattern. These authors compared the growth forms, reproductive systems and modes of pollination in this family, and suggested that the more primitive tree or shrub habit and an allogamous reproductive system are associated with ornithophily. Gottsberger (1986) reported that hummingbirds probably have influenced the origin of the ornithophilous flowers of Malvaceae in the Neotropics. Parallel with this bird pollination, the staminal column might have formed by the fusion of the filaments to protect the ovary (Grant, 1950). This adaptive character is manifest in flowers of all recent members of this family. The position of flowers is especially designed for exploration by hummingbirds. Chiropterophily has developed in Malvaceae more recently from ornithophilous ancestors within neotropical forest regions. The woody, forest inhabiting, and probably also chiropterophilous and allogamous species, show a tendency towards an increase in height and larger flowers with a more accentuated nectar secretion for foraging by bats (Vogel, 1969). Together with the diversification of the Malvaceae and their migration into the more open regions, pollination by bees apparently has become prominent. When compared with ornithophilous members within a genus, the entomophilous species are often lower woody plants, occasionally remaining shrubby, but more often herbaceous perennial or annual (Gottsberger, 1986).

Malachra capitata displays an herbaceous habit and grows in open areas. The morning anthesis, pollen and nectar production during morning 
period, and the exposure of flower base indicate that it is adapted for pollination by day-active foragers. The conspicuous floral displays, nontubular nature of the flower, and the small volume of nectar with high sugar concentration are shown to be entomophilous characteristics (Baker \& Baker, 1983; Faegri \& van der Pijl, 1979). The filaments arise all along the entire length of the staminal column; here the column and style are short and situated within the corolla. These floral characteristics of $M$. capitata conform to entomophilous pollination syndrome and are in conformity with the floral characteristics stated by Gottsberger (1986). The flowers attract bees and butterflies but bees serve as principal pollinators; the body washings of bees and butterflies for pollen confirm this. Burkill (1916) reported that this plant is pollinated by Xylocopa latipes, and it is a principal pollinator of $M$. capitata at our study areas. Burkill also mentioned that black ants visit the flowers of $M$. capitata; in the present study, Camponotus ants are resident foragers and visit the flowers throughout the flowering season.

Malachra capitata is self-compatible since selfed flowers set mature fruits as observed in hand-pollination tests. But, the low fruit set in autogamy shows that even self-pollination is largely vector-dependent. The highest fruiting through cross-pollination in this plant suggests that it is primarily an out-crosser. This dual breeding system ensures fruit set in the presence or absence of insects and such ability is especially important in new areas where pollinators are not reliable or available. With mixed breeding system, and the hectic foraging activity of bees and butterflies, the plant shows $21 \%$ fruit set in open-pollination. This fruit set rate could be related to the inherent ability, significant percentage of flower predation by Brachinus and Mylabris beetles, and the nutrient levels in the soil environment. The mixed breeding system functioning in this species is surely a fail-safe strategy to ensure the success of sexual reproduction through which it colonizes and expansion of its population size is ensured during its growth season.

In Malachra capitata, the fruit is a schizocarp, a characteristic of Malvaceae species (Solomon Raju, 2007). The mature schizocarps divide into mericarps each of which bears a single seed; the mericarps are indehiscent and hence their decomposition in the soil is a pre-requisite for seed germination. The new plants emerge from the seed during the rainy season mostly in the parental sites suggesting short distance seed dispersal is the norm. Since the seed stock occurs in the parental sites, they usually result in pure stands.

\section{Recommendations}

Malachra capitata is an oviparous species. New plants emerge from the seeds mostly at the parental sites during rainy season. Since $M$. capitata occurs either in small patches or in pure stands, it provides the required levels of nutrients through its pollen and nectar to local insects. The same insects also effect pollination of true mangrove plant species which occur at different salinity zones from land side to sea side (Jonathan \& Solomon Raju 2009). Therefore, flower-insect interactions of $M$. capitata play an important role in supporting pollinator species of true mangrove species in all areas of its distribution. Seed bank of this plant species must be maintained in situ to ensure its annual recurrence and provide the local insects the necessary forage during its flowering season and also to bind and stabilize the loose soil of margins of mangrove forest during rainy season.

\section{Literature cited}

Baker, H. G. and Baker, I. 1983. A brief historical review of the chemistry of floral nectar. Pp. 126-152, In: Bentley, B. and T. Elias (eds.). The Biology of Nectaries. Columbia University Press, New York.

Burkill, I. H., 1916. Notes on the pollination of flowers in India. Journal and Proceedings of Asiatic Society of Bengal, 2: 241-265.

Cruden, R. W., 1977. Pollen-ovule ratios: A conservative indicator of breeding systems in flowering plants. Evolution, 31: 32-46.

Dafni, A., P. G. Kevan and B. C. Husband, 2005. Practical Pollination Biology. Enviroquest Ltd., Ontario: 590.

Faegri, K. and L. van der Pijl, 1979. The Principles of Pollination Ecology. Pergamon Press, New York: 291.

Gottsberger, G., 1967. Blutenbiologische Beobachtungen an brasilianischen Malvaceen. 
Osterreichische botanische Zeitschrift, 114: 349378.

Gottsberger, G., 1972. Bluenbiologische Beobachtungen an brasilianischen Malvaceen II. Osterreichische botanische Zeitschrift, 120: 439509.

Gottsberger, G., 1986. Some pollination strategies in Neotropical savannas and forests. Plant Systematics \& Evolution, 152: 29-45.

Grant, V., 1950. The protection of the ovules in flowering plants. Evolution, 4: 179-201.

Jonathan, K. H. and A. J. Solomon Raju, 2009. Insect pollination and self-planting seed dispersal strategy in the true viviparous mangrove tree species Ceriops tagal (Perr.) C. B. Robinson (Rhizophoraceae). Journal of Threatened Taxa, 1: 133-140.

Pandit, S. and B. C. Choudhury, 2001. Factors effecting pollinator visitation and reproductive success in Sonneratia caseolaris and Aegiceras corniculatum in the mangrove forest in India. Journal of Tropical Ecology, 17: 431-447.

Sazima, M., 1981. Pollinizacao de duas especies de Pavonia (Malvaceae) por beija-flores, na Serra do Cipo, Minas Gerais. Revista Brasileira de Biologia, 41: 733-737.

Solomon Raju, A. J., 1990. Observations on the floral biology of certain mangroves. Proceedings of Indian National Science Academy, 56: 367374.

Solomon Raju, A. J., 2007. Indian Plant Reproductive Ecology and Biodiversity. Today \& Tomorrow's Printers and Publisher, New Delhi: 383.

Solomon Raju, A. J. and K. H. Jonathan, 2008. Reproductive ecology of mangrove trees Ceriops decandra (Griff.) Ding Hou and Ceriops tagal (Perr.) C.B. Robinson (Rhizophoraceae). Acta Botanica Croatica, 67: 201-208.

Solomon Raju, A. J., K. H. Jonathan and A. Vijaya Lakshmi, 2006. Pollination biology of Ceriops decandra (Griff.) Ding Hou (Rhizophoraceae), an important true viviparous mangrove tree species. Current Science, 91: 1235-1238.
Solomon Raju, A. J., C. Subba Reddi and B. Sujatha, 1994. Pollination in mangrove plants. Journal of Nature Conservation, 6: 89-96.

Subba Reddi, C. and A. J. Solomon Raju, 1997. Reproductive biology of three mangrove plant species. Indian Journal of Forestry, 20: 153-157.

Vogel, S. T., 1969. Chiropterophilie in der neotropischen Flora. Neue Mitteilungen II. Spezieller Teil (Fortsetzung). Flora Abteilung B, Morphologie und Geobotanik,158: 185-222. 